\title{
Clinical Utility of An Implantable Cardioverter-Defibrillator Lead With A Floating Atrial Sensing Dipole: A Single-Center Experience
}

\author{
Sabri Seyis ${ }^{{ }^{*}}$, Özge Kurmuş ${ }^{2}$, Hasan Turhan ${ }^{1}$ \\ ${ }^{1}$ Department of Cardiology, Istinye University Liv Hospital, Istanbul, Turkey \\ ${ }^{2}$ Department of Cardiology, Ufuk University, Ankara, Turkey
}

Corresponding Author: Sabri Seyis, Department of Cardiology, Istinye University Liv Hospital, Istanbul, Turkey, Tel: +90 212 4446623; E-mail: sabriseyis@yahoo.com

Received: 14 December 2017; Accepted: 22 December 2017; Published: 28 December 2017

\begin{abstract}
Background: Single-chamber ICD systems with the ability to sense the atrium have been developed. We describe the operation characteristics, atrial and ventricular sense performance of the lead, atrial and ventricular tachyarrhythmia recordings, and appropriate and inappropriate shock treatments in patients who receive a single lead ICD with a floating atrial sensing dipole in our center.
\end{abstract}

Methods: We retrospectively analyzed the data of 58 patients (44 male, $59.3 \pm 4.41$ years) who were implanted with a Lumax 540 VR-T DX device with a Linox Smart S DX lead. The pacemaker records of the patients were analyzed monthly for 12 months. All of the recorded tachyarrhythmia episodes were examined by 2 cardiologists and atrial/ventricular discrimination was performed. We also compared with SMART algorithm.

Results: A total of 24 tachycardia episodes with rapid ventricular response were detected in 7 patients. Three of them, which were in the VF zone, were treated by ICD appropriately without using the SMART algorithm. Nine of 21 tachycardia episodes were evaluated as VT by SMART algorithm. The visual analysis showed that VT attacks were detected correctly by the algorithm. Twelve tachycardia episodes were evaluated as SVT by the algorithm. No treatment was applied by ICD. It was confirmed in visual analysis. A total of 38 atrial tachycardia episodes were detected in 8 patients. Visual analysis confirmed that these attacks were correctly detected by the SMART algorithm.

Conclusions: Single lead ICD systems with atrial dipole provide reliable atrial recordings during sinus rhythm and arrhythmias. 
Keywords: Atrial Sensing; İmplantable Cardioverter Defibrillator; Tachyarrhythmias, Atrial Sensing; Complications

\section{Introduction}

Implantable cardioverter defibrillators (ICDs) are known to prolong survival by reducing the risk of sudden death in high-risk patient groups. Particularly, there is a debate about whether a single or dual chamber pacemakers should be implanted in patients who do not need a pacemaker. In the majority of patients with ICD implants, single chamber systems are preferred [1]. However, inappropriate shocks seen in single-chamber pacemakers affect patients' quality of life negatively. In previous studies, inappropriate shocks from supraventricular tachyarrhythmia have been reported in approximately $11.5 \%-17.4 \%$ of patients with ICD implants [2,3]. An atrial sensing mode that can differentiate supraventricular tachyarrhythmia (SVT) from ventricular tachyarrhythmia (VT) will reduce the risk of inappropriate shocks [4-6].

Furthermore, continuous monitoring of the atrium may provide very useful information in terms of atrial arrhythmias. Atrial fibrillation is the most common arrhythmia in patients with heart failure and AF has been detected in 1/3 of patients without atrial arrhythmia within 3 years after ICD implantation [7]. Early detection of AF is useful in two ways. The first is to identify the most important cause of improper shocks, AF, and to prevent inappropriate shocks $[3,8,9]$. The second is to identify the patients with AF, to start antiarrhythmic therapy in these patients and perhaps more importantly to prevent thromboembolic events by starting anticoagulant treatments [10].

However, a lead should also be placed in the atrium to monitor the atrium. Placing an extra lead in the atrium prolongs the procedure, increases cost, and increases complication rates [1,11-13]. In a previous study, the periprocedural complications and the risk of in-hospital mortality were increased with dual chamber devices compared to the single chamber devices [11]. Similarly, Peterson et al. showed that dual chamber ICDs had a twofold increased risk for cardiac tamponade and mechanical complications compared to single chamber ICDs [1].

Therefore, single-chamber ICD systems with the ability to sense the atrium have been developed. The system with Linox Smart S DX lead has been shown to be safe and effective [14-18]. In this article, we describe the operation characteristics, atrial and ventricular sense performance of the lead, atrial and ventricular tachyarrhythmia recordings, and appropriate and inappropriate shock treatments in patients who receive single lead ICD with atrial dipole in our center.

\section{Materials and methods}

\subsection{Patients}

We retrospectively analyzed the data of 58 patients who did not require a pace and were implanted according to appropriate indications. All patients were implanted with a Lumax 540 VR-T DX device with a Linox Smart S DX lead. Patients were older than 18 years of age and all patients who were included in the study were in sinus rhythm. 


\subsection{Biotronic DX ICD System and SMART Algorithm}

The lead is a ventricular lead [7,8] with atrial bipolar sense, and there are 2 electrode rings at $150 \mathrm{~mm}$ distance to the lead tip (Figure 1). Atrial electrodes are in the atrium and are not in direct contact with myocardium (Figure 2). Geometric area of each atrial electrode is $24.5 \mathrm{~mm}^{2}$ and they are coated in porous form. This coating facilitates the detection of intracardiac signals by expanding the electrochemical active surface area 1000 times [19]. DX ICD devices do not have an atrial pace feature, but can be operated in VDD mode if desired. To prevent the loss of atrial signals, DX devices use an amplifier that increases the atrial gain by 4 fold (Figure 3). High-gain atrial signals are then filtered to distinguish them from signal frequencies outside the atrial signal ranges $(30-70 \mathrm{~Hz})$.

DX ICD devices use SMART algorithm for tachyarrhythmia discrimination. This algorithm analyzes the relationship between heart rate, velocity stability, and atrial and ventricular activity in pulses (Figure 4). The specificity of the SMART algorithm for detecting ventricular tachycardia (VT) is $89 \%$ and it's sensitivity is $100 \%$ $[20]$.

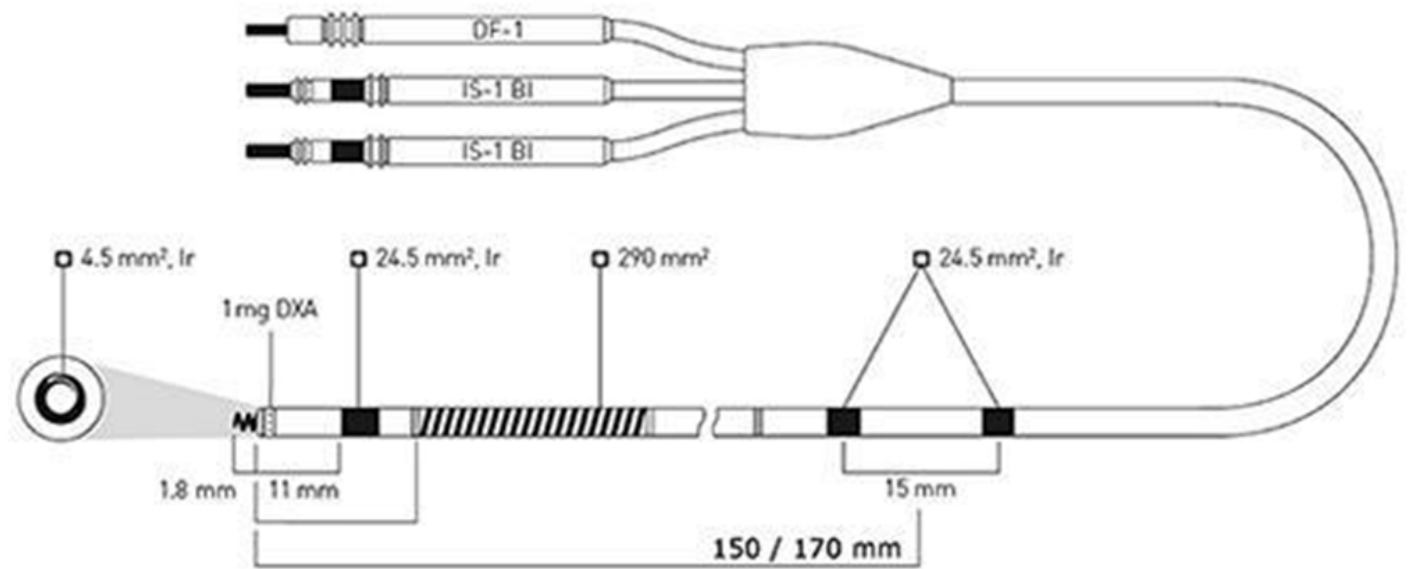

Figure 1: Active-fixation, steroid-eluting Linoxsmart S DX lead (BIOTRONIK SE \& Co KG) has two integrated atrial sensing rings mounted 150 or $170 \mathrm{~mm}$ from the lead tip. The electrically active $\left(4.5 \mathrm{~mm}^{2}\right)$ extendable and retractable screw and the adjacent ring electrode $\left(24.5 \mathrm{~mm}^{2}\right)$ provide bipolar sensing and pacing in the right ventricle. Defibrillation shocks and low- or high-energy cardioversion shocks are delivered from a single coil (290 $\mathrm{mm}^{2}$ ). . DXA = dexamethasone acetate; $\mathrm{Ir}=$ fractal iridium coating; pentapolar lead connector: DF-1=Defibrillation coil; IS-1=International Standard 1; Bi=Bipolar.

\subsection{Implantation Procedure}

Implantation procedures were performed according to the standards of our center. Implant location, lead position and X-ray duration were recorded. Post-procedure electrical measurements such as P and R wave amplitudes, pacing threshold values and impedances were recorded. A standard VT or VF zone was not set. 


\subsection{Follow-up}

The pacemaker records of the patients were analyzed monthly for 12 months. All of the recorded tachyarrhythmia episodes were examined by 2 cardiologists and atrial/ventricular discrimination was performed. Also, they were compared with SMART algorithm. Inappropriate shocks have been identified.

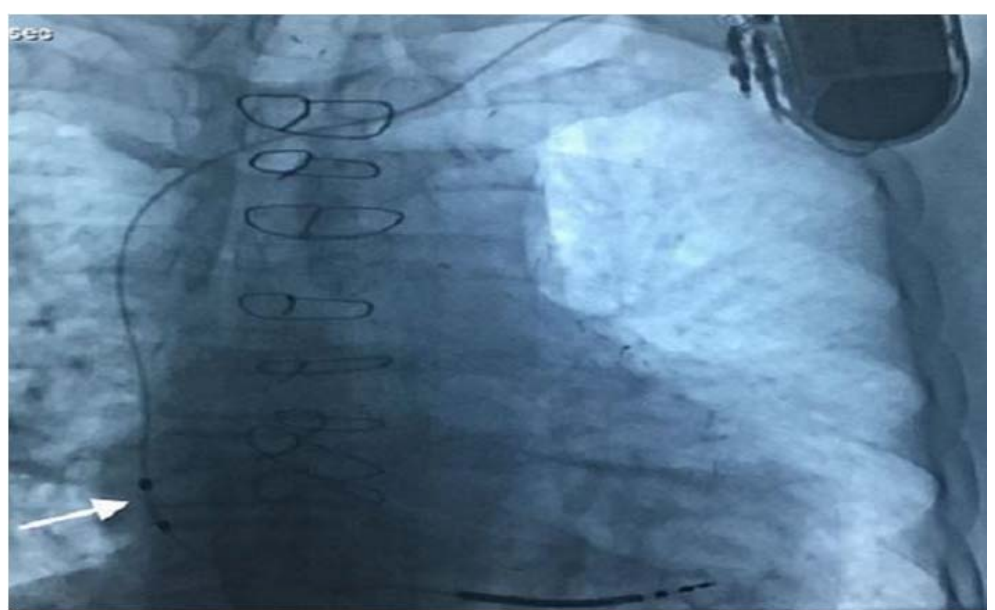

Figure 2: A patient with the Linoxsmart S DX lead implanted. Note the floating atrial dipole is positioned in the high-mid right atrium (arrow).

\section{ICD sensing circuit}

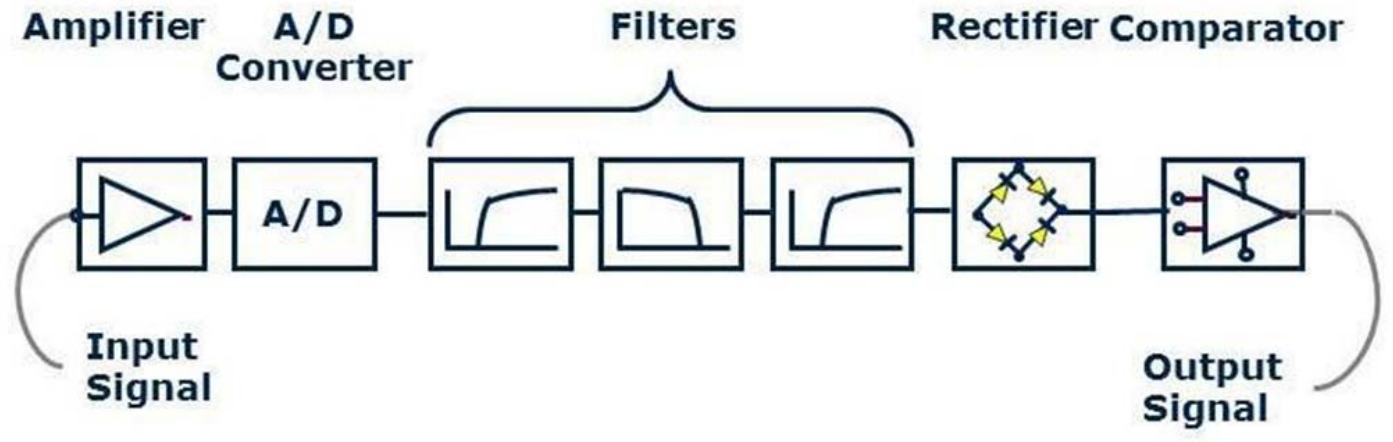

Figure 3: The schematic shows atrial signal processing in the Biotronik DX ICD system, which includes a dedicated atrial input stage with up to 4-fold signal amplification and noise filtering. 


\section{SMART Detection ${ }^{\mathrm{TM}}$ Algorithm}

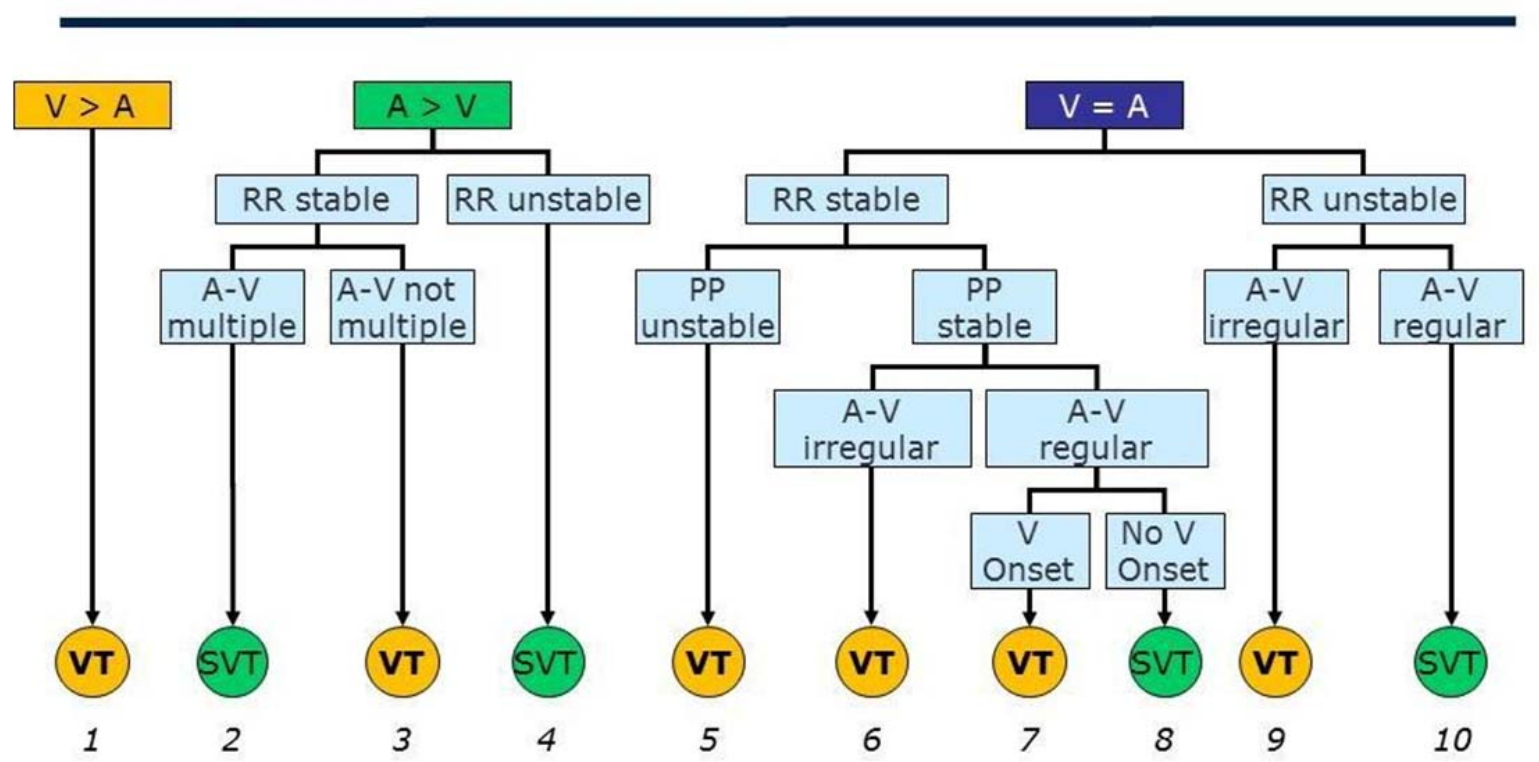

Decision tree with 10 branches

Figure 4: The step-by-step tachycardia analysis by the SMART detection algorithm. Three "branches" are presented: ventricular rate faster than atrial rate $(\mathrm{RR}<\mathrm{PP})$; ventricular rate and atrial rate equal $(\mathrm{RR}=\mathrm{PP})$; ventricular rate slower than atrial rate $(\mathrm{RR}>\mathrm{PP})$. $\mathrm{SVT}=$ supraventricular tachycardia; $\mathrm{VT}=$ =ventricular tachycardia.

\subsection{Statistical analysis}

The data were analyzed as mean and standard deviation. Linear mixed model analysis was used to compare the impedance measurements with the P-wave and R-wave changes in the follow-up. The SAS program MIXED procedure (version 9.4) was used for statistical analysis.

\section{Results}

\subsection{Patients}

A total of 58 patients were included in the study. All patients were implanted with a Lumax 540 VR-T DX device with a Linox Smart S DX lead. Forty-four (75.9\%) of the patients were male. The mean age of the patients was 59.3 \pm 4.41 years. There were indications for primary protection in 40 patients $(69 \%)$, whereas ICD was implanted in 18 patients $(31 \%)$ for secondary protection. Mean EF values of the patients were $30.4 \pm 4.66 \%$. The general characteristics of the patients are summarized in Table 1.

\begin{tabular}{|l|l|l|l|}
\hline Parameters & \multicolumn{3}{|l|}{} \\
\hline Gender n(\%) & Female & 14 & -24.1 \\
\hline & Male & 44 & -75.9 \\
\hline
\end{tabular}




\begin{tabular}{|c|c|c|c|}
\hline ICD indication & $\begin{array}{l}\text { Primary } \\
\text { prevention }\end{array}$ & \multicolumn{2}{|l|}{$40(69)$} \\
\hline & $\begin{array}{l}\text { Secondary } \\
\text { prevention }\end{array}$ & 18 & -31 \\
\hline $\begin{array}{l}\text { Implantation } \\
\text { location }\end{array}$ & $\begin{array}{l}\text { Left } \\
\text { subclavian }\end{array}$ & 58 & -100 \\
\hline \multirow[t]{2}{*}{ Lead position } & Septum & \multicolumn{2}{|l|}{$2(3.4)$} \\
\hline & Apical & 56 & -96.6 \\
\hline \multirow[t]{2}{*}{$\begin{array}{l}\text { Ventricular } \\
\text { tachycardia }\end{array}$} & No & 49 & -84.5 \\
\hline & Yes & \multicolumn{2}{|l|}{$9(15.5)$} \\
\hline \multirow[t]{2}{*}{$\begin{array}{l}\text { Supraventricular } \\
\text { tachycardia }\end{array}$} & No & 43 & -74.1 \\
\hline & Yes & 15 & -25.9 \\
\hline \multirow{2}{*}{ Atrial fibrillation } & No & 50 & -86.2 \\
\hline & Yes & \multicolumn{2}{|l|}{$8(13.8)$} \\
\hline Complication & No & \multicolumn{2}{|l|}{$58(100)$} \\
\hline \multirow[t]{2}{*}{ Inappropriate shock } & No & \multicolumn{2}{|l|}{$57(98.3)$} \\
\hline & Yes & \multicolumn{2}{|l|}{$1(1.7)$} \\
\hline
\end{tabular}

Table 1: General characteristics of the patients $(n=58)$

\subsection{Implantation}

The mean duration of fluoroscopy was $3.81 \pm 0.76$ minutes. The left subclavian region was the preferred ICD implant site for all patients. In $56(96.6 \%)$ of the patients, the lead was placed in the apical position. During implantation of the device, $\mathrm{P}$ wave amplitude was $3.54 \pm 0.74 \mathrm{mV}$; $\mathrm{R}$ wave amplitude was $12.8 \pm 2.11 \mathrm{mV}$; ventricular pacing threshold was $0.79 \pm 0.13 \mathrm{~V}$; ventricular pacing impedance was $561 \pm 54.8 \mathrm{Ohm}$; and the shock impedance was 73.9 \pm 9.76. Implantation information is summarized in Table 2. Amplified $P$ wave amplitudes also showed differences during follow-up, but no statistical difference was observed. No change was observed in $\mathrm{R}$ wave amplitudes and threshold values.

\begin{tabular}{|l|c|c|}
\hline Parameters & Mean & SD \\
\hline Age (years) & 58.3 & 4.41 \\
\hline EF(\%) & 30.4 & 4.66 \\
\hline P wave sense (mV) & 3.54 & 0.7 \\
\hline Fluoroscopy duration (minutes) & 3.81 & 0.76 \\
\hline R wave sense (mV) & 12.8 & 2.11 \\
\hline Pacing threshold (V) & 0.79 & 0.13 \\
\hline
\end{tabular}




\begin{tabular}{|l|l|l|}
\hline Pacing impedance $(\Omega)$ & 561 & 54.8 \\
\hline Shock impedance $(\Omega)$ & 73.9 & 9.76 \\
\hline
\end{tabular}

Table 2: Implantation data of the patients $(n=58)$

\subsection{Arrhythmia Analysis}

A total of 24 tachycardia with rapid ventricular response were detected in 7 patients. Since 3 of them were in the VF zone, they were treated by ICD appropriately without using the SMART algorithm. In one of the patients who were treated with this shock, it was detected that the shock was given inadequately as a result of over-perception of highfrequency non-physiological signals. Nine of 21 tachycardia episodes were evaluated as VT by SMART algorithm. The remaining 6 episodes ( 3 episodes were non sustained VT) were treated according to the treatment programmed by the device. The visual analysis performed by cardiologists showed that VT attacks were detected correctly by the algorithm. Twelve tachycardia episodes were evaluated as SVT by the algorithm, based on parameters such as equal atrial and ventricular velocity, stable atrial and ventricular rhythm, and constant PR interval. The device did not apply treatment. It was confirmed in visual analysis.

\subsection{Atrial Arrhythmia Analysis}

A total of 38 atrial tachycardia episodes were detected in 8 patients. Of these, 23 AF episodes were evaluated in 3 patients without previous AF history. It was confirmed by visual analysis that these attacks were correctly detected by the SMART algorithm and not treated.

\section{Discussion}

In this article we shared the experience of our center with a single-lead ICD system with atrial sense ability. In fact, this concept was introduced in the 1980s with the insertion of VDD pacemakers to protect AV synchronicity in patients with complete AV block and preserved sinus node function [21]. However, instabilities in the atrial sense lead to the loss of AV synchronicity, and currently less than $1 \%$ of pacemakers implanted in the USA is in this mode [22]. However, the majority of ICD patients does not need a place during implantation and the risk of symptomatic bradycardia is also low [23]. In a recently published study, only $7 \%$ of patients undergoing subcutaneous ICD required a pace [24].

It has been shown that dual-chamber devices are better than single-chamber devices to distinguish supraventricular arrhythmias, but this benefit has not been clearly demonstrated for inappropriate shocks [25]. Despite the advantages of recognizing and distinguishing tachycardias, the increased risk of complications of second lead, the risk of mortality and morbidity, and the use of dual-chamber devices remain limited [11,26,27]. The LinoxSMART S DX system which was designed and developed for this purpose has efficacy similar to dual chamber systems, with complication rates as low as single chamber devices [28]. 
Since a separate lead was not placed in atrium, the duration of the procedure and the duration of total fluoroscopy were low $(3.81 \pm 0.76 \mathrm{~min}]$. This duration is similar to the one in previous studies conducted with this lead $[16,18]$. It is also shorter than 6.25 minutes measured in single-lead dual-chamber ICD systems [29].

The main problem in single chamber systems is that there is not enough atrial sense. In our study, the mean P wave amplitude was $3.54 \pm 0.74 \mathrm{mV}$ during the process. During the follow-up, the P waves amplified by the device were checked and no significant decrease in the amplitudes was detected. Stazi et al. have shown that atrial signals can be amplified up to 4 folds [17]. Other studies using the DX ICD system have also found that the stability of atrial signals is acceptable $[18,30]$. In the study by Iori et al., daily $\mathrm{P}$ wave measurements were made using the Biotronic Home Monitoring system and a mean value of $4.2 \pm 1.9 \mathrm{mV}$ was obtained during the 200 day period. The measured $\mathrm{R}$ waves were stable over time [30].

In the ADRIA study, 249 patients were randomized to DX ICD and conventional dual chamber ICD systems [16]. Both arms were found to be similar in terms of discrimination of supraventricular arrhythmia. The specificity in discrimination of supraventricular tachycardia was $61.8 \%$ in the DX arm and $66.2 \%$ in the other group. The published clinical experience with the new generation of DX is limited. A total of 88 spontaneous tachyarrhythmia episodes were detected in 23 patients in the Linox DX study. All 15 ventricular attacks were detected and successfully treated. In $74 \%$ of non-ventricular tachyarrhythmias, treatment was stopped appropriately [18].

In our study, all but one of the ventricular tachycardia and ventricular fibrillation attacks were correctly detected and treated by the device. In the patient with improper shock, it was found that the overperception of high frequency non-physiological signals resulted in improper shock. It seems that there is a lower rate of inappropriate shocks compared to other studies [18,31]. Twelve of episodes with high ventricular rate were evaluated as SVT by SMART algorithm based on parameters such as equal atrial and ventricular velocity, stable atrial and ventricular rhythm, and constant PR interval. Previous studies have shown that the SMART algorithm succeeds in VT discrimination at high ventricular rate [30]. It has been determined that DX ICD can successfully distinguish supraventricular tachycardia in our study. Paroxysmal AF attacks were detected in 3 patients who were not previously diagnosed with AF. Anticoagulant treatment was initiated and the risk of thromboembolism was reduced in these patients. In the ASSERT study, $10.1 \%$ of patients developed atrial tachyarrhythmia during a 3-month period [7]. Daily assessments with remote monitoring systems has proven impact on the early recognition of atrial tachyarrhythmia and the risks, and the effectiveness of treatment [10,32-35]. Especially diagnosis and treatment of subclinical AF patients at an early stage significantly reduces mortality and morbidity [36].

Also recently, devices with double-coiled lead are being questioned. Defibrillation thresholds of ICD devices with single-coiled leads were not significantly different from those of ICD devices with dual-coiled leads. [37-40] Especially when double-coiled leads need to be removed, there are major problems. Both fibrous tissue development and adhesion of the coil to the thin RV wall complicate the removal procedure [41-45]. In a large study of 2064 lead 
removal procedures, it was shown that complication rates were higher when removing devices with double-coiled lead, which is 2.6 times more difficult when considering some criteria [46].

In this study, a small number of patients and arrhythmia events were retrospectively investigated. However, the number of patients is higher than other studies in the literature. The ability of the DX ICD system to distinguish arrhythmia has not been specifically investigated in this study. No special programming has been done to reduce inappropriate shocks. There is a need for further work on improper shocks. Perhaps the most important limitation is that home monitoring is not used in the measurement of $\mathrm{P}$ waves in patients.

\section{Conclusion}

Single lead ICD systems with atrial dipole provide reliable atrial recordings during sinus rhythm and arrhythmias. The specialist can have the necessary knowledge that can discriminate SVT/VT and detect early AF without placing a second lead. In addition, procedural difficulties and subsequent complications brought about by a second lead are avoided.

\section{Disclosure and Conflict of Interest}

None

\section{References}

1. Peterson PN, Varosy PD, Heidenreich PA, Wang Y, Dewland TA, et al. Association of single- vs dual-chamber ICDs with mortality, readmissions, and complications among patients receiving an ICD for primary prevention. JAMA 309 (2013): 2025-2034.

2. Poole JE, Johnson GW, Hellkamp AS, Anderson J, Callans DJ, et al. Prognostic importance of defibrillator shocks in patients with heart failure. N Engl J Med 359 (2008): 1009-1017.

3. Daubert JP, Zareba W, Cannom DS, McNitt S, Rosero SZ, et al. Inappropriate implantable cardioverterdefibrillator shocks in MADIT II: Frequency, mechanisms, predictors, and survival impact. J Am Coll Cardiol 51 (2008): 1357-1365.

4. Friedman PA, McClelland RL, Bamlet WR, Acosta H, Kessler D, et al. Dual-chamber versus singlechamber detection enhancements for implantable defibrillator rhyrhm diagnosis: The detect supraventricular tachycardia study. Circulation 113 (2006): 2871-2879.

5. Theuns DA, Rivero-Ayerza M, Boersma E, Jordaens L. Prevention of inappropriate therapy in implantable defibrillators: A metaanalysis of clinical trial comparing single-chamber and dualchamber arrhythmia discrimination algorithms. Int J Cardiol 125 (2008): 352-357.

6. Francia P, Balla C, Uccellini A, Cappato R. Arrhythmia detection in single- and dual-chamber implantable cardioverter defibrillators: The more leads, the better? J Cardiovasc Electrophysiol 20 (2009): 1077-1082.

7. Healey JS, Connolly SJ, Gold MR, Israel C, Van Gelder IC, et al. Subclinical atrial fibrillation and the risck of stroke. N Engl J Med 366 (2012): 120-129. 
8. Rees JB, Borleffs JW, de Bie MK, Stijnen T, van Erven L, et al. Inappropriate implantable cardioverterdefibrillator shocks: Incidence, predictors, and impact on mortality. J Am Coll Cardiol 57 (2011): 556-5562.

9. Powell BD, Saxon LA, Boehmer JP, Day JD, Gilliam III FR, et al. Survival after shock therapy in implantable cardioverter-defibrillator and cardiac resynchronization therapy-defibrillator recipients according to rhythm shocked: The ALTITUDE survival by rhythm study. J Am Coll Cardiol 62 (2013): 1674-1679.

10. Ricci RP, Morichelli L, Santini M. Remote control of implanted devices through Home MonitoringTM technology improves detection and clinical management of atrial fibrillation. Europace 11 (2009): 54-61.

11. Dewland TA, Pellegrini CN, Wang Y, Marcus GM, Keung E, Varosy PD. Dual-chamber implantable cardioverter-defibrillator selection is associated with increased complication rates and mortality among patients enrolled in the NCDR implantable cardioverter-defibrillator registry. J Am Coll Cardiol 58 (2011): 1007-1013.

12. Friedman PA, Bradley D, Koestler C, Slusser J, Hodge D, et al. A prospective randomized trial of single- or dual-chamber implantable cardioverter-defibrillators to minimize inappropriate shock risk in primary sudden cardiac death prevention. Europace 16 (2014): 1460-1468.

13. Shurrab M, Elitzur Y, Healey JS, Gula L, Kaoutskaia A, et al. VDD vs DDD pacemakers: A meta-analysis. J Cardiol 39 (2014): 138-139.

14. Niehaus M, de Sousa M, Klein G, Korte T, Pfeiffer D, et al. Chronic experiences with a single lead dual chamber implantable cardioverter defibrillator system. Pacing Clin Electrophysiol 26 (2003):1937-1943.

15. Schuchert A, Niehaus M, Binner L, Belke R, Meinertz T. Feasibility of atrial sensing via a free-floating singlepass defibrillation lead for dual-chamber defibrillators. J Interv Card Electrophysiol 8 (2003):209-214.

16. Sticherling C, Zabel M, Spencker S, Meyerfeldt U, Eckardt L, et al. Comparison of a novel, single-lead atrial sensing system with a dual-chamber implantable cardioverter defibrillator system in patients without antibradycardia pacing indications: Results of a randomized study. Circ Arrhythm Electrophysiol 4 (2011): 5663.

17. Stazi F, Mampieri M, Cardinale M, Laudadio MT, Gargaro A, Del Giudice GB. Implant and long-term evaluation of atrial signal amplification in a single-lead ICD. Pacing ClinElectrophysiol 35 (2012): 1119-1125.

18. Safak E, Shmitz D, Konorza T, Wende C, De Ros JO, et al. Clinical efficacy and safety of an implantable cardioverter defibrillator lead with a floating atrial sensing dipole. Pacing Clin Electrophysiol 36 (2013): 952962.

19. Schaldach M. Fractal coated leads: Advanced surface technology for genuine sensing and pacing. Prog Biomed Res 5 (2000): 259-272.

20. Sinha AM, Stellbrink C, Schuchert A, Mox B, Jordaens L, et al. Clinical experience with a new detection algorithm for differentiation of supraventricular from ventricular tachycardia in a dual-chamber defibrillator. $\mathrm{J}$ Cardiovasc Electrophysiol 15 (2004): 646-652.

21. Antonioli GE. Single lead atrial synchronous ventricular pacing: A dream come true. Pacing Clin Electrophysiol 17 (1994): 1531-1547.

22. Gillis AM, Russo AM, Ellenbogen KA, Swerdlow CD, Olshansky B, et al. HRS/ACCF expert consensus statement on pacemaker device and mode selection. J Am Coll Cardiol 60 (2012): 682-703. 
23. Sweeney MO, Ellenbogen KA, Tang ASL, Whellan D, Mortensen PT, et al. Atrial pacing or ventricular back up-only pacing in implantable -cardioverter defibrillators. Heart Rhythm 7 (2010): 1552-1560.

24. Giovanni Luca Botto, Giovanni B. Forleo, Alessandro Capucci et al. 'AIAC S-ICD Why Not' Survey Investigators; The Italian subcutaneous implantable cardioverter-defibrillator survey: S-ICD, why not?. Europace 2016 euw337.

25. Deisenhofer I, Kolb C, Ndrepepa G, et al. Do current dual chamber cardioverter defibrillators have advantages over conventional single chamber cardioverter defibrillators in reducing inappropriate therapies?A randomized, prospective study. J Cardiovasc Electrophysiol 12 (2001):134-142.

26. Gilliam FR, Hayes DL, Boehmer JP, et al. Real World Evaluation of Dual-Zone ICD and CRT-D Programming Compared to Single-Zone Programming:TheALTITUDE REDUCES Study. Journal of Cardiovascular Electrophysiology 22 (2011): 1023-1029.

27. Poole JE, Gleva MJ, Mela T, et al. Complication Rates Associated With Pacemaker or Implantable Cardioverter-Defibrillator Generator Replacements and Upgrade Procedures Results From the REPLACE Registry. Circulation 122 (2010): 1553-1561.

28. Safak E, Schmitz D, Konorza T, Wende C, Schirdewan A. Assessment of atrial sensing quality in ICD patients with a floating atrial dipole ICD lead (interim results). Europace 13 (2011): 1027.

29. Niehaus M, Schuchert A, Thamasett S, Pfeiffer D, Korte T, Pichlmaier M, Panning B, et al. Multicenter experiences with a single lead electrode for dual chamber ICD systems. Pacing Clin Electrophysiol 24 (2001): 1489-1493.

30. Iori M, Giacopelli M, Quartieri F, Bottoni N, Manari A. Implantable Cardioverter Defibrillator System with Floating Atrial Sensing Dipole: A Single-Center Experience. Pacing Clin Electrophysiol 37 (2014): 1265-1273.

31. Worden NE, Alqasrawi M, Mazur A. Long Term Stability and Clinical Utility of Amplified Atrial Electrograms in a Single-Lead ICD System with Floating Atrial Electrodes. Pacing Clin Electrophysiol 39 (2016): 1327-1334.

32. Ricci RP, Morichelli L, Gargaro A, Laudadio MT, Santini M. Home monitoring in patients with implantable cardiac devices: Is there a potential reduction of stroke risk? Results from a computer model tested through Monte Carlo simulations. J Cardiovasc Electrophysiol 20 (2009): 1244-1251.

33. Ip J, Waldo AL, Lip GY, Rothwell PM, Martin DT, et al. Multicenter randomized study of anticoagulation guided by remote rhythm monitoring in patients with implantable cardioverter-defibrillator and CRT-D devices: Rationale, design, and clinical characteristics of the initially enrolled cohort The IMPACT study. Am Heart J 158 (2009): 364-370.

34. Israel CW. Optimizing the treatment of atrial fibrillation: Contributions by remote monitoring. Europace 11 (2009): 7-8.

35. Varma N, Epstein AE, Irimpen A, Schweikert R, Love C. Efficacy and safety of automatic remote monitoring for implantablecardioverter defibrillator follow-up: The Lumos $\mathrm{T}$ Safely Reduces Routine Office Device Follow-up (TRUST) trial. Circulation 122 (2010): 325-332.

36. Keach JW, Bradley SM, Turakhia MP, Maddox TM. Early detection of occult atrial fibrillation and stroke prevention. Heart 101 (2015): 1097-1102. 
37. Manolis AS,Chiladakis J, Maounis TN, Vassilikos V, Cokkinos DV. Two coil versus single coil transvenous cardioverter defibrillator systems: Comparative data. Pacing Clin Electrophysiol 23 (2000): 1999-2002.

38. Schulte B, Sperzel J, Carlsson J, Schwarz T, Ehrlich W, et al. Dual coil vs single coil active pectoral implantable defibrillator lead systems: Defibrillation energy requirements and probability of defibrillation success atmultiples of the defibrillation energy requirements. Europace 3 (2001): 177-180.

39. RinaldiCA, Simon RD, Geelen P, Reek S, Baszko A, et al. A randomized prospective study of single coil versus dual coil defibrillation in patients with ventricular arrhythmias undergoing implantable cardioverter defibrillator therapy. Pacing Clin Electrophysiol 26 (2003): 1684-1690.

40. Mokkabberi R, Haftbaradaran A, Shruthi P, Haftbaradaran A, Pranesh S, et al. Abstract 17919:Defibrillation thresholds in single versus dual coil lead systems: Is there any difference? Circulation 124 (2011): A17919.

41. Haqqani HM, Mond HG. The implantable cardioverter defibrillator lead: Principles, progress, and promises. Pacing Clin Electrophysiol 32 (2009): 1336-1353.

42. Kennergren C, Bjurman C, Wiklund R, Gäbel J. A single centre experience of over one thousand lead extractions. Europace 11 (2009): 612-617.

43. Małecka B, Kutarski A, Grabowski M. Is the transvenous extraction of cardioverter-defibrillator leads more hazardous than that of pacemaker leads? Kardiol Pol 68 (2010): 884-890.

44. Cooper JM, Stephenson EA, Berul CI, Walsh EP, Epstein LM. Implantable cardioverter defibrillator lead complications and laser extraction in children and young adults with congenital heart disease: Implications for implantation and management. J Cardiovasc Electrophysiol 14 (2003): 344-349.

45. Bracke F. Complications and lead extraction in cardiac pacing and defibrillation. Neth Heart J 16 (2008): S28S31.

46. Epstein AM, Love CJ, Wilkoff BL, Chung MK, Hackler JW, Bongiorni MG, et al. Superior vena cava defibrillator coils make transvenous lead extraction more challenging and riskier. J Amer Coll Cardiol 61 (2013): 987-989.

This article is an open access article distributed under the terms and conditions of the Creative Commons Attribution (CC-BY) license 4.0 